\title{
Cost Impact of Using Patients' Own Multidose Medications in Hospital
}

\author{
Gigi Y C Wong
}

\begin{abstract}
Background: The use of patients' own medications may allow minimization of drug wastage and costs. However, the cost impact of this practice, taking into account the time that pharmacy personnel spend on verification, is unknown.
\end{abstract}

Objectives: To determine the cost impact of using patients' own multidose medications within a surgical population, relative to the cost of routine dispensing; to describe the prescribing of multidose medications with regard to type, prevalence, quantity, and formulary status; and to determine the percentage of medications suitable for use after verification.

Methods: In this prospective, consecutive, time-and-motion case series, admission orders for patients newly admitted to 6 surgical units were screened to identify patients' own multidose medications that required verification. The total time required for all verification-related activities was captured. Data were collected over 3 weeks in early 2011.

Results: Of the 250 patients admitted, 51 (20.4\%) had a prescription for one of their own multidose medications. Verification was completed for $67(79 \%)$ of 85 prescribed items, of which 61 (91\%) were deemed suitable for use. Thirty-five different medication types were identified. Of the 85 prescribed medications, 57 (67\%) were on formulary. The most common routes of administration for these 85 prescribed items were inhalation (56 [66\%]), nasal (9 [11\%]), and ophthalmic (8 [9\%]). The average cost \pm standard deviation was $\$ 24.54 \pm \$ 32.33$ per multidose item. The average time required for verification was $10.5 \pm 6.7 \mathrm{~min}$ per patient $(4.8 \pm 3.3 \mathrm{~min}$ per medication). The cost impact was calculated as the difference between the drug cost with routine hospital dispensing and the cost of verifying home medications, where a positive value indicated a lower cost with verification of home medications (i.e., a saving for the hospital). The average cost impact was $\$ 40.05 \pm \$ 42.60$ per patient $(p<0.001$ by 1 -sample $t$ test) $(\$ 18.85 \pm \$ 15.42$ per medication). A total cost saving of $\$ 1601.85$ was realized.

Conclusions: Using patients' own multidose medications instead of routine dispensing resulted in a cost saving of $74 \%$, including labour costs for verification by the pharmacist.

Keywords: cost impact, patients' own medications, multidose medications, hospital

Can J Hosp Pharm. 2014;67(1):9-16

\section{RÉSUMÉ}

Contexte : L'utilisation des propres médicaments des patients peut permettre de réduire le gaspillage et les coûts de médicaments. Par contre, la répercussion sur les coûts de cette pratique, en tenant compte du temps passé par le personnel de la pharmacie à la vérification, est inconnue.

Objectifs : Déterminer la répercussion sur les coûts de l'utilisation des propres médicaments multidoses des patients chez une population de personnes ayant subi une intervention chirurgicale, par rapport aux coûts de la distribution habituelle; décrire la prescription de médicaments multidoses relativement au type, à la prévalence, à la quantité et à l'inscription sur la liste des médicaments (formulaire thérapeutique); et déterminer le pourcentage de médicaments pouvant être utilisés, après vérification.

Méthodes : Dans cette série prospective analysant les temps et mouvements de cas consécutifs, les ordonnances d'admission de patients nouvellement admis dans six différentes unités de soins chirurgicaux ont été examinées afin d'identifier quels étaient les propres médicaments multidoses des patients devant être vérifiés. Le temps total nécessaire pour effectuer l'ensemble des activités de vérification a été noté. Les données ont été recueillies sur une période de trois semaines au début de 2011.

Résultats : Des 250 patients admis, 51 (20,4\%) avaient une prescription pour un de leurs propres médicaments multidoses. Une vérification a été effectuée pour 67 (79\%) des 85 médicaments prescrits dont 61 (91\%) ont été jugés aptes à l'utilisation. On a identifié 35 différents types de médicament. Des 85 médicaments prescrits, 57 (67\%) étaient inscrits sur la liste des médicaments. Les voies d'administration les plus courantes parmi ces 85 médicaments étaient l'inhalation (56 [66\%]), la voie nasale (9 [11 \%]) et la voie oculaire (8 [9\%]). Le coût moyen \pm l'écart-type était de $24,54 \$ \pm 32,33 \$$ par médicament multidose. Le temps moyen nécessaire pour la vérification était de $10,5 \pm 6,7$ minutes par patient $(4,8$ \pm 3,3 minutes par médicament). La répercussion sur les coûts a été calculée comme étant la différence entre le coût des médicaments s'ils avaient été délivrés selon le circuit habituel de l'hôpital et le coût de la vérification des médicaments apportés par les patients. Une valeur positive indiquait que la vérification des médicaments apportés par les patients était moins coûteuse, donc une économie pour l'hôpital. La moyenne de la répercussion sur les coûts était de $40,05 \$ \pm 42,60 \$$ par patient $(p<0,001$ au moyen du test $\mathrm{T}$ pour échantillon unique) $(18,85 \$ \pm 15,42 \$$ par médicament). Une économie de coûts de 1601,85 \$ a été réalisée.

Conclusions : Utiliser les propres médicaments multidoses des patients plutôt que de faire appel à la délivrance habituelle de médicaments par l'hôpital s'est traduit par une économie de coûts de 74 \%, ce qui tient compte des frais de personnel pour la vérification par le pharmacien.

Mots clés : répercussion sur les coûts, propres médicaments des patients, médicaments multidoses, hôpital

[Traduction par l'éditeur] 


\section{INTRODUCTION}

$\mathrm{H}^{\circ}$ ospitals are considered the largest category of Canadian government expenditure, accounting for $\$ 59$ billion in 2011 and projected to reach $\$ 62.6$ billion in $2013 .{ }^{1}$ The rate of expenditure for drugs in hospitals, estimated at $4.5 \%$ for fiscal year 2002/2003, is increasing. ${ }^{2}$ Unit-dose drug distribution systems are cited by Accreditation Canada as best practice, ${ }^{3}$ and are also endorsed by the Canadian Society of Hospital Pharmacists (CSHP). ${ }^{4}$ In a unit-dose system, medications for a 24- $\mathrm{h}$ period are dispensed in a ready-to-administer form, with advantages of safety and reduced wastage or pilferage ${ }^{5}$ however, where a unit-dose format is not possible (e.g., inhalers, creams, eye drops), medications are supplied in multidose format. One way to reduce hospital drug costs may be the use of patients' own medications, particularly multidose medications.

According to CSHP guidelines for drug-use control, ${ }^{6}$ policies and procedures shall provide for the use of patients' own medications, and such medications shall be verified. For a home medication to be used in hospital, it must be identifiable, approved for use in Canada, and uncompromised in terms of its integrity, and the benefits of use must outweigh the risks.

In a survey of Canadian pharmacy directors, $98 \%$ of the 86 hospitals represented by survey responses permitted the use of patients' own medications. ${ }^{7}$ Six (86\%) of the 7 hospitals that actively encouraged the use of patients' own medications allowed multidose medications. The main advantages included cost savings, decreased inventory, and reduced delays. The authors of the study noted that the cost and benefit of using patients' own medications needed further examination.

There is a paucity of published studies specific to the cost impact of using patients' own medications in hospital. ${ }^{8-10}$ In a systematic review, Lummis and others ${ }^{8}$ evaluated 18 studies on several parameters, such as wastage (i.e., unused or destroyed items) and drug costs saved. They concluded that the benefits of using patients' own medications included decreased wastage of drugs and budget savings, but they noted that workload concerns must be addressed. One of the studies included in the review, which had been conducted in New Brunswick, ${ }^{9}$ explored the impact of using home medications in a pilot program and estimated the time for verification by a pharmacist at $13 \mathrm{~min} /$ patient. Drug cost savings were estimated at $\$ 200000$ per year if the program were implemented hospitalwide. The study also found improvements in patient care with the use of home medications, such as increased pharmacist visibility. Another study examined the financial implications of re-engineering clinical pharmacy services in the hospital, which introduced the use of patients' own medications. ${ }^{11}$ The hospital dispensary avoided some workload, and a cost saving was achieved.
The current study was conducted at the Charlton Campus of St Joseph's Healthcare Hamilton, an acute care teaching hospital with more than 600 beds in Hamilton, Ontario. This hospital permits the use of patients' own medications, provided the medications have been verified as per hospital policy. Although the use of patients' own medications is not required, this approach is of particular interest because of the potential to minimize drug wastage and costs. This study examined use of patients' own medications in a surgical population, as the length of stay for these patients is shorter than for patients in other units, and the modification of drug therapy for chronic conditions is less likely. ${ }^{10}$ Furthermore, because the supply of a multidose medication from the hospital pharmacy may outlast the patient's duration of stay, there is a potentially greater cost impact if these patients use their own supply. Because workload is one of the concerns that has been identified in relation to use of patients' own medications, ${ }^{8}$ this study was designed to prospectively capture the time required by pharmacy personnel to complete verification.

The primary objective of this study was to determine the cost impact of using patients' own multidose medications within a surgical patient population, relative to the cost of routine hospital dispensing. End points were personnel (pharmacist) time for the verification process and net difference between the labour cost for verification and the cost of the prescribed product. Secondary objectives were to describe the prescribing of multidose medications with regard to type, prevalence, quantity, and formulary status, and to determine the percentage of multidose medications suitable for use in hospital after verification.

\section{METHODS}

In this prospective, consecutive time-and-motion case series, data were collected over a 3-week period (March 21 to April 8, 2011), on Mondays to Fridays from 0700 to 0900 . The study was conducted on 6 surgical units with a total of 115 beds: surgical/gastrointestinal (43 beds), musculoskeletal (30 beds), urology (16 beds), head and neck unit ( 7 beds), chest unit (12 beds), and surgical step-down ( 7 beds).

Patients were included if they had been admitted to the unit within the previous $24 \mathrm{~h}$ and if a multidose medication had been prescribed on admission. Patients were excluded if they had not been newly admitted to the unit, if a multidose medication had not been prescribed, if a multidose item had already been supplied by the inpatient pharmacy, or if the patient had been transferred between units. For the purposes of this study, a multidose medication was defined as any medication supplied by the manufacturer or the supplier in such a manner that repeated doses could be obtained from the same container, not including dosettes or compliance packages. All forms of insulin and lactulose were excluded. 
Verification time was defined as the total amount of time required to verify a home medication. The verification time included time for any conversation with the patient or caregivers (e.g., self-introduction of pharmacist, description of purpose of visit), locating the home medication on the unit, donning personal protective equipment as required, revisiting the same patient if he or she was not available the first time, travelling to reach the patient's bedside from the nursing station, documenting as per hospital policy (initials on a sticker attached to the medication), and documenting in the computer system. The flow of activities for the study is outlined in Figure 1, starting from the screening of orders to decisions based on urgency and whether the item was available on the unit. Time was recorded with a digital clock, which was started upon arrival of the investigator (G.Y.C.W.) on the unit for the purpose of verifying multidose medications. The start and stop times were recorded at all time points until each medication was verified or dispensed by the inpatient pharmacy, or until the patient was discharged. If the prescribed item could not be obtained (i.e., nonformulary), the order was referred to the unit pharmacist for alternatives, a process that was beyond the scope of this project.

\section{Data Analysis}

The cost impact (either per patient or per medication) was calculated according to the following general formula:

cost impact $=$ drug acquisition cost cost of home medication verification

where the drug acquisition cost refers to the cost of routine hospital dispensing, and the cost of home medication verification consists of the labour cost for verification time and the drug acquisition cost if dispensing was required after verification.

A 1-sample $t$ test was conducted. The null hypothesis was that the cost impact was equal to 0 , where $\alpha=0.05$. The drug acquisition costs (2011 data) were obtained from another staff

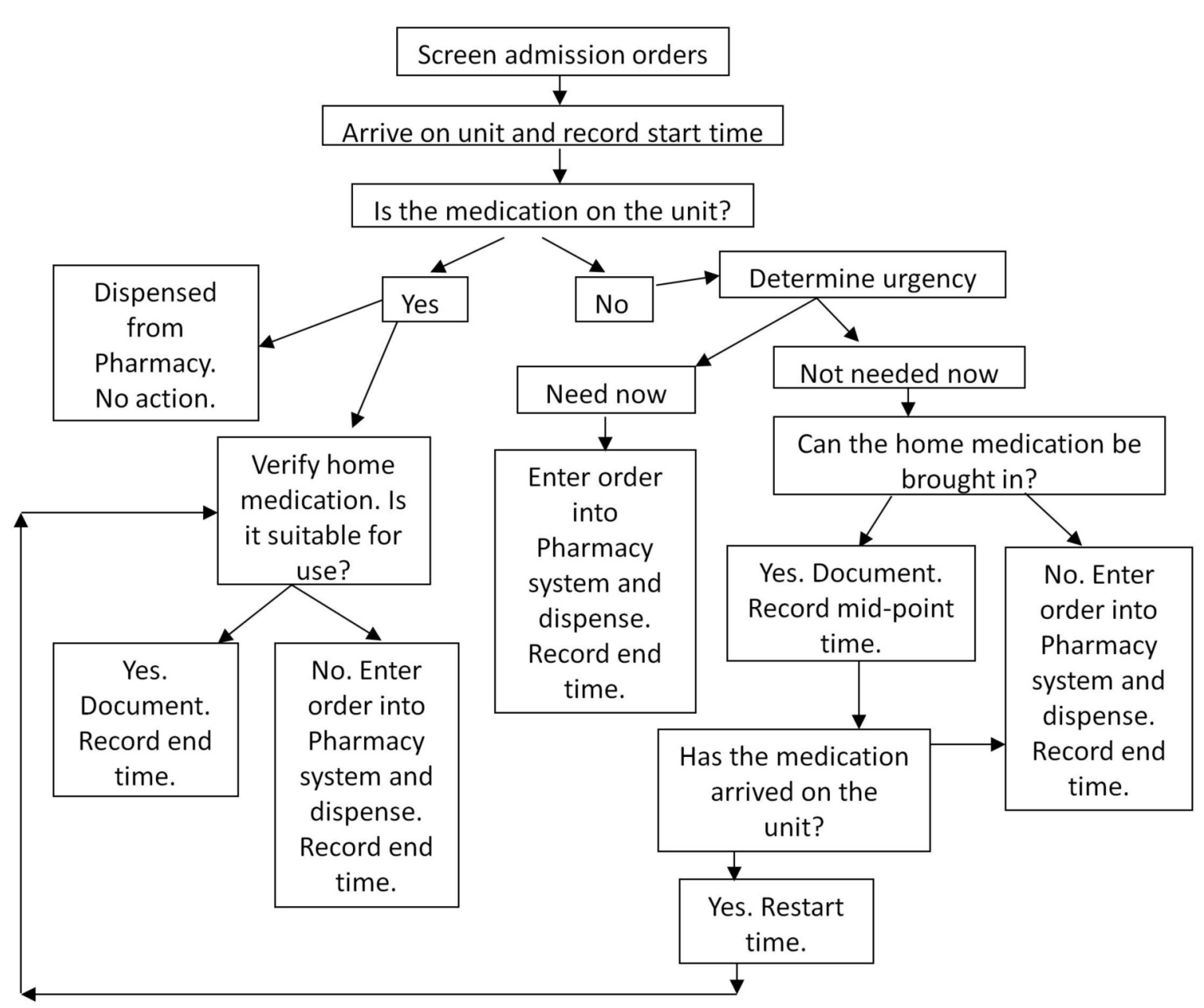

Figure 1. Flow chart showing pharmacists' activities for data collection to determine the cost impact of using patients' own medications. 
member (the Inpatient Pharmacy Drug Utilization Assistant). The mean cost \pm standard deviation (SD) for a prescribed item and the mean amount of time \pm SD per patient (and per medication) were calculated. Data on precise times for every patient were summed to calculate the total time required for verification, which was then used to determine mean labour cost \pm SD for verification per patient (and per medication). Under the Ontario Public Service Employee Union (OPSEU) contract, ${ }^{12}$ all nonmanagerial hospital pharmacists reach the top hourly rate within 5 years. Because the majority of pharmacists on staff were already at the top rate at the time of study, the top rate of $\$ 48.93 / \mathrm{h}$ (not including benefits) was used for labour cost calculations.

The number of patients admitted and the percentage of patients for whom multidose medications were prescribed on admission were captured. The mean number of items \pm SD per patient was calculated. The percentages of multidose medications on formulary versus not on formulary were also determined. The percentage of medications considered suitable for use after verification was calculated.

\section{RESULTS}

A total of 250 patients were admitted to the 6 study units over the 3-week study period; for 51 (20.4\%) of these patients, a multidose medication was prescribed. Forty of these patients met the inclusion criteria, with a total of 85 items prescribed (mean 2 items per patient). Eleven of the 51 patients were excluded because the item had already been supplied by the pharmacy.

The prescribed multidose medications were grouped by route of administration according to Health Canada's Drug Product Database. ${ }^{13}$ The most common routes were inhalation (56 [66\%]), nasal (9 [11\%]), and ophthalmic (8 [9\%]). Less common routes were topical $(6[7 \%])$, oral (3 [4\%]), sublingual (2 [2\%]), and transdermal (1 [1\%]). Fifty-seven (67\%) of the 85 prescribed items were on formulary. A total of 35 different medication types were identified. Accounting for the prescribing frequency for each of the 85 items, the mean cost of a multidose medication was $\$ 24.54 \pm \$ 32.33$. The top 7 active ingredients prescribed are listed in Table 1.

\section{Table 1. Top 7 Active Ingredients in Multidose Medications* Prescribed for Patients in This Study}

\begin{tabular}{|c|c|c|}
\hline Active Ingredient & Formulary Status* & $\begin{array}{l}\text { Total No. } \\
\text { of Prescriptions }\end{array}$ \\
\hline Salbutamol $(100 \mu \mathrm{g})$ & Formulary & 18 \\
\hline $\begin{array}{l}\text { Salmeterol + fluticasone (Advair) } \\
(50 \mu \mathrm{g} / 250 \mu \mathrm{g}, 50 \mu \mathrm{g} / 500 \mu \mathrm{g} \text { Diskus, } \\
\text { or } 25 \mu \mathrm{g} / 250 \mu \mathrm{g} \mathrm{MDI})\end{array}$ & $\begin{array}{l}\text { Formulary and } \\
\text { nonformulary }\end{array}$ & 7 \\
\hline Tiotropium $18 \mu \mathrm{g}$ (Spiriva) & Formulary & 7 \\
\hline $\begin{array}{l}\text { Budesonide + formeterol } 200 \mu \mathrm{g} / 6 \mu \mathrm{g} \\
\text { turbuhaler (Symbicort) }\end{array}$ & Formulary & 4 \\
\hline Fluticasone propionate $(125 \mu \mathrm{g}$ or $250 \mu \mathrm{g})$ & Formulary & 4 \\
\hline Mometasone furoate 50 mg (Nasonex) & Nonformulary & 4 \\
\hline Latanoprost 0.005\% (Xalatan) & Nonformulary & 4 \\
\hline
\end{tabular}

\section{Table 2. Summary of Time and Labour Costs}

\begin{tabular}{lcc} 
Factor & Verification Time (min)* & Labour Cost (\$)† \\
\hline Total for study & $410(6.84 \mathrm{~h})$ & 334.56 \\
Average per patient & $10.5 \pm 6.7$ & $8.58 \pm 5.44$ \\
Average per medication & $4.8 \pm 3.3$ & $3.94 \pm 2.73$ \\
\hline *Verification time was defined as the total amount of time required to verify a home \\
medication; it includes conversation time with the patient or caregivers (self-introduction \\
of pharmacist, purpose of visit), locating the home medication on the unit, donning \\
personal protective equipment as required, revisiting the same patient if the patient \\
was not available the first time, travelling to reach the patient's bedside from the \\
nursing station, documenting as per hospital policy (initials on a sticker attached to the \\
medication), and documenting in the computer system. \\
tUnionized pharmacist rate: $\$ 48.93 / \mathrm{h}$.
\end{tabular}


The verification process was completed for 67 (79\%) of the 85 identified multidose items, and 61 (91\%) of these were considered suitable for use. The time for verification and the associated labour costs are summarized in Table 2. Figure 2 compares the total cost of routine hospital dispensing (i.e., drug acquisition cost only, as no verification was required) with the cost of using patients' own multidose medications, for which verification was required (as well as drug acquisition cost, if dispensing was required after verification). Over the 3-week period of the study, use of patients' own medications resulted in a saving of $\$ 1601.85$ to the hospital, with the pharmacist's labour costs taken into account. The mean cost impact \pm SD per patient (for the 40 patients) was $+\$ 40.05 \pm 42.60$ dollars $(p<0.001 ; 95 \%$ confidence interval $-\$ 45.15$ to $+\$ 125.56)$. The cost impact per medication (for the 85 items prescribed) was $\$ 18.85 \pm 15.42(p<0.001 ; 95 \%$ confidence interval $-\$ 11.99$ to +49.69$)$. A positive value for cost impact indicates a saving, and a negative value indicates a greater expense.

\section{DISCUSSION}

The main purpose of this study was to determine the cost impact of using patients' own multidose medications on admission to a surgical unit, as compared with routine hospital dispensing. The results showed that using patients' own multidose medications in hospital resulted in a saving of approximately $74 \%$ for the hospital, even when labour costs for verification by a pharmacist were included.

\section{Consideration of Multidose Medications for Inclusion or Exclusion}

This study did not collect data for all multidose medications. Insulin was excluded because of concerns about hyperglycemia or hypoglycemia secondary to a potential delay in screening of admission orders. Lactulose was excluded because it was readily available on all study units. As per hospital policy, medications in blister packages were excluded (because they required approval from the pharmacy manager), as were dosettes. Oral contraceptives were also excluded. Tiotropium capsules for inhalation (Spiriva; strip of 5 capsules) and its corresponding inhaler device (Handihaler) were captured as separate items. Because AeroChamber inhalation devices were dispensed by the Inpatient Pharmacy, they were also considered as multidose medications and were therefore included in the analysis.

\section{Verification Process}

This study has documented a reliable estimate of the time required to complete the verification process (Table 2). The average time per patient, $10.5 \pm 6.7 \mathrm{~min}$, was comparable to a previously published estimate of $13 \mathrm{~min} .{ }^{8}$ The average for the

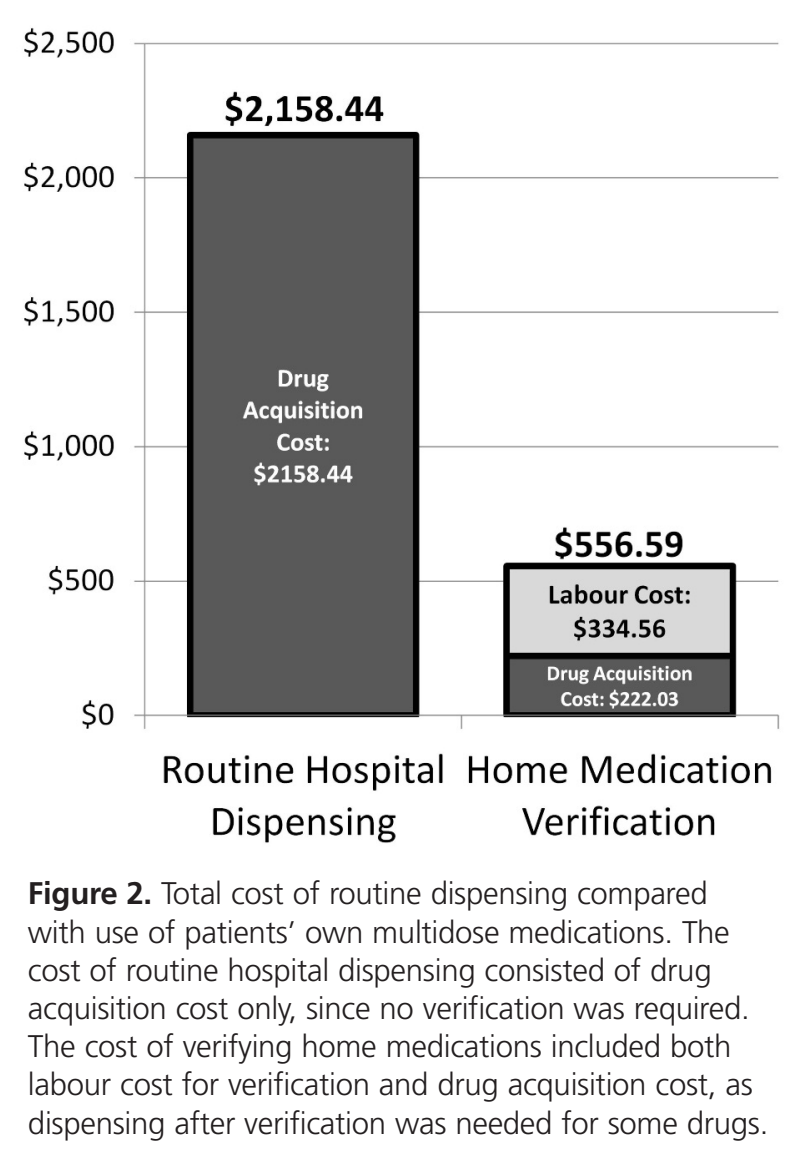

\section{Box 1. Reasons to Revisit the Same Patient to Complete the Verification Process}

Patient had gone for a test or procedure

Patient was being seen by another health care provider Patient did not want to interact with the pharmacist

Patient was asleep

Family or friend was to bring in the home medication Patient's belongings had not yet arrived at the bedside To return the medication(s) to the patient

\begin{tabular}{l} 
Box 2. Variables Affecting Duration of Verification \\
Visit \\
\hline Language barriers \\
Eagerness of the patient to converse \\
Clarity of the labelling \\
Ease of locating the patient's own medication \\
Distractions (interruptions, questions, or requests)
\end{tabular}

current study may have been slightly less than the estimate because only multidose items were considered. The average time per medication was $4.8 \pm 3.3$ minutes (Table 2). As described above, the time required for verification involved more than identifying the medication. In particular, it was sometimes necessary to revisit the same patient to complete the 
verification process (see Box 1), and a number of variables affected the duration of the visit (as reported in Box 2).

The verification process was also an opportunity to identify whether the patient had been using the medication routinely before admission. In instances where the patient had not been using the multidose medication regularly (e.g., an as-needed cream), the situation was considered not urgent, and the investigator determined whether or not the home supply could be brought into hospital for verification. If discussion with the patient revealed that the prescribed multidose item did not in fact reflect the home regimen, and no supply was dispensed, the cost for verification captured only labour costs. If appropriate, the physician would have been notified, although no situations requiring such notification occurred during the study period.

\section{Cost Impact and Annual Cost Savings}

The cost impact per patient was \$40.05 \pm 42.60 $(p<0.001)$. Therefore, $68 \%$ of the time, the cost impact ranged from $-\$ 2.55$ to $+\$ 82.65$. Comparing the costs of routine hospital dispensing with the cost of verifying home medication (as in the cost impact formula shown above), a total saving of $\$ 1601.85$ (74\% of the total cost of routine dispensing) was calculated for the 3-week study period. Extrapolated to a 1-year period, the saving was estimated at nearly $\$ 28000$.

In fact, the true cost impact may be more dramatic. The amount of time required for verification, as recorded in this study, may have been an overestimation, because verification of medications (requesting that medications be brought in, performing visual examination, etc.) may be completed as part of pharmacists' medication reconciliation activities, regardless of whether patients' home medications are to be used in hospital. Hence, performing verification at the same time as medication reconciliation may be the most efficient approach. Also, when the home supply is used, the workload of the hospital dispensary is bypassed. These potential cost savings were not evaluated in this study.

\section{Verification by Pharmacist versus Pharmacy Assistant or Technician}

In this study, cost savings were realized when a pharmacist completed the verification. Delegating this work to a pharmacy assistant or technician might liberate more clinical time for the pharmacist and generate even greater cost savings. To test this idea, the costs were recalculated, assuming that a pharmacy assistant or technician would require the same amount of time as a pharmacist to complete the verification process and using the top unionized rate for a pharmacy assistant or technician as per the OPSEU agreement ${ }^{12}$ (Table 3 ). Even though the labour cost for a pharmacy assistant or technician is $45 \%$ less than the labour cost for a pharmacist, the corresponding cost saving to the institution reflects an increase of only about $7 \%$ or about $\$ 2000$ annually. This result suggests that the majority of cost savings is attributable to savings in drug acquisition costs.

\section{Dispensing versus Verification}

In situations of increased workload and competing priorities, these study results can be used to extrapolate when it might be cost-effective for a pharmacist to verify a patient's own multidose medication for use in hospital, relative to dispensing the drug. Using the calculated average labour cost of $\$ 8.58 \pm$ $\$ 5.44$ per patient as the cost threshold, verification of items

Table 3. Cost Comparison for Verification Performed by a Pharmacist versus a Pharmacy Assistant

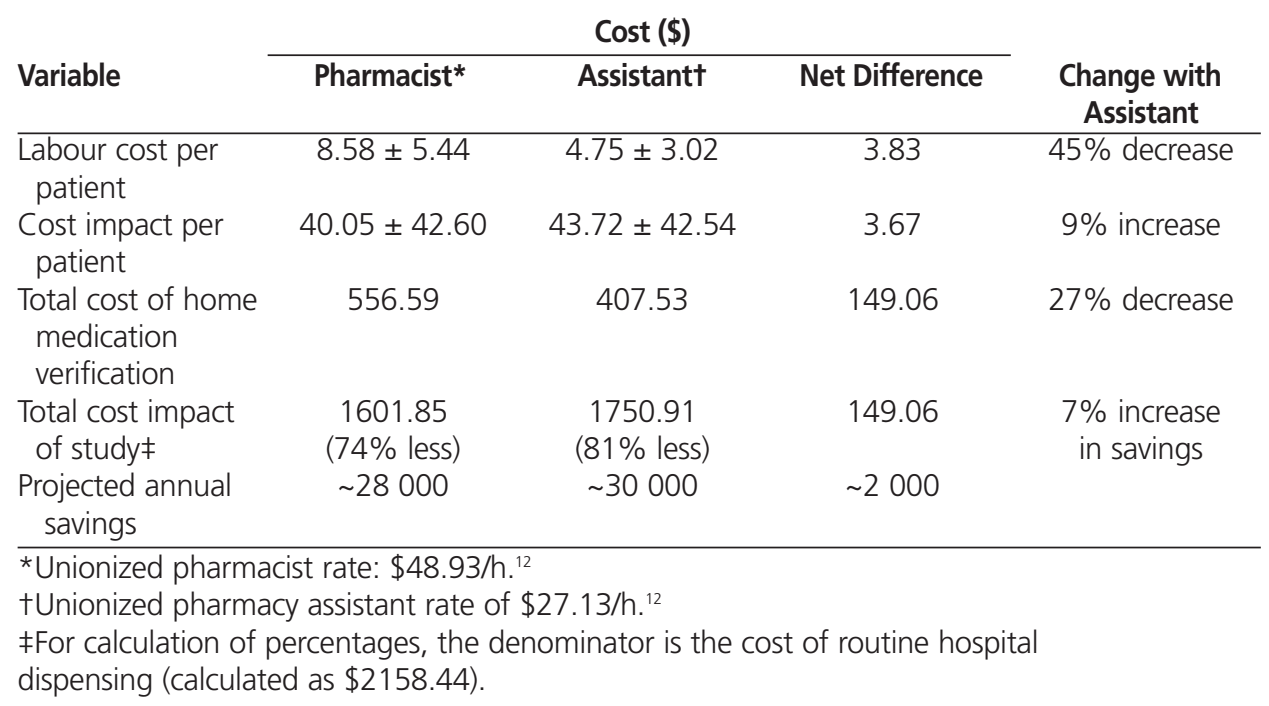


costing more than $\$ 14.02$ (mean $+1 \mathrm{SD}$ ) would usually be cost-effective. This rule of thumb may help pharmacists to decide if verifying a home medication is "worth" their time. At the time of the current study, of the top 7 active ingredients (Table 1), only salbutamol and tiotropium would not be cost-effective to verify. Explicit costs for individual drugs are not disclosed because of restrictions in contract agreements.

\section{Suitability of Home Medications for Use by Hospital Inpatients}

In this study, a product's packaging and labelling were most often used for identification. Medications were deemed unsuitable for use if they were expired or had been tampered with, or if product sterility and integrity could not be determined. Some of these assessments were based on visual inspection for colour and appearance. Similar parameters have been examined to assess suitability for use in previous studies. ${ }^{910}$

In this study, most of the items (61 [91\%] of 67 items verified) were considered suitable for use after verification. This result affirms those of another study, which reported that $89.6 \%$ of items were suitable for use. ${ }^{10}$ Items considered unsuitable for use had expired $(n=4)$, were broken $(n=1)$, or were visibly unclean or deteriorated $(n=1)$. In cases where the items were deemed unsuitable for use, the drug was dispensed by the dispensary if required.

\section{Barriers to Verification}

Verification was completed for $79 \%$ of the multidose items prescribed (i.e., 67 of 85 items). The reasons for not completing verification for the 18 other items are listed in Table 4.

\section{Patients' Own Medications and the Canada Health Act}

Previous authors have discussed whether the use of a patient's home medication adheres with legislation. ${ }^{14}$ The Canada Health Act states that drugs are part of hospital services if they are medically necessary. ${ }^{15}$ Regulation 552 of the Health Insurance Act of Ontario ${ }^{16}$ states that drugs are part of insured

\section{Table 4. Reasons for Not Completing the Verification Process}

\begin{tabular}{lc} 
Reason & No. of Cases \\
\hline Medication was not brought to hospital & 7 \\
\hline $\begin{array}{l}\text { Patient did not have anyone to bring the } \\
\text { home medication to the hospital }\end{array}$ & 4 \\
\hline $\begin{array}{l}\text { Patient had been discharged home by the } \\
\text { time of pharmacist's revisit follow-up }\end{array}$ & 4 \\
\hline $\begin{array}{l}\text { New medication for the patient, admitted } \\
\text { via emergency }\end{array}$ & 3 \\
\hline Total & 18 \\
\hline
\end{tabular}

hospital services. Flood and Choudhry ${ }^{17}$ noted that the Canada Health Act seems to have the underlying assumption that all care provided by a physician is medically necessary and that the term "medically necessary" lacks a specific definition, ${ }^{17,18}$ because it needs to encompass all circumstances ${ }^{17}$ and ensure the equitable allocation of resources. ${ }^{18}$ If a multidose item is prescribed in hospital regardless of the patient's most accurate home regimen, or is unrelated to the reason for admission, the multidose medication may not be required and hence, the Canada Health Act would not apply.

Legislation exists on the provision of drugs to patients, but to this author's knowledge, there is no explicit legislation as to whether the use of patients' own medications is prohibited. The Ontario Hospital Association (OHA) does not have any policies or position statements regarding the use of patients' own medications, and an OHA representative indicated that each hospital would have its own policies on that matter (S. Kutty, Director, Patient Safety, Physician and Professional Issues, Ontario Hospital Association; personal communication, May 3, 2011). As previously noted, the author's hospital has developed its own policy, as per CSHP guidelines, ${ }^{6}$ and a national survey revealed that $98 \%$ of hospitals responding permitted the use of patients' own medications.?

\section{Strengths and Limitations of the Study}

Few studies have documented the cost impact of using patients' own multidose medications with consideration of labour costs. In the study reported here, prospective data collection captured the steps before, during, and after verification during all weekday hours of pharmacy operation (Monday to Friday, 0700 to 0900). This study also captured the prescribing patterns for multidose medications in a surgical patient population.

The study did not account for reductions in labour costs due to bypassing the dispensary. Although there were no instances during the study period when procurement of nonformulary items by the dispensary required considerable effort, the time for this task was similarly not captured by the study design. If a nonformulary multidose item was prescribed, the cost of providing the prescribed product was determined, instead of substitution with a formulary alternative. If various sizes of the same medication were available, the most common size was used for the cost calculation. Because the process of medication verification did not encompass the entire process of medication reconciliation, the labour time may be an overestimate, as several steps of the verification process overlap with medication reconciliation. Labour costs reflected only the highest hourly rate for pharmacists at this institution. Verification was performed by a clinical pharmacist in the patient care areas, and hence the time required in other institutions may vary, because of differences in procedures across institutions. 


\section{CONCLUSIONS}

The cost impact of using patients' own multidose medications relative to the cost of standard hospital dispensing was not equal to zero. A cost saving of $74 \%$ was observed, even when labour costs for a pharmacist to conduct medication verification were considered. Multidose medications were prescribed on admission for about one-fifth of surgical patients, and most of the items verified were deemed suitable for use.

\section{References}

1. National health expenditure trends: 1975 to 2013. Ottawa (ON): Canadian Institute for Health Information; [cited 2014 Jan 23]. Available from: https://secure.cihi.ca/estore/productSeries.htm?pc=PCC52

2. Hospital trends in Canada: results of a project to create a historical series of statistical and financial data for Canadian hospitals over twenty-seven years. Ottawa (ON): Canadian Institute for Health Information; 2005 [cited 2010 Nov 22]. Available from: https://secure.cihi.ca/free_products/Hospital_ Trends_in_Canada_e.pdf

3. Qmentum Program standards: managing medications. Ottawa (ON): Accreditation Canada; 2010.

4. Canadian hospital pharmacy 2015 (CSHP 2015): CSHP goals and objectives for pharmacy practice in hospitals and related healthcare settings to be achieved by 2015. Ottawa (ON): Canadian Society of Hospital Pharmacists; 2007 [cited 2014 Jan 23]. Available from: www.cshp.ca/programs/ cshp2015/index_e.asp

5. Drug distribution: statement on unit-dose and intravenous admixture. Ottawa (ON): Canadian Society of Hospital Pharmacists; 2008 [cited 2010 Dec 30]. Available from: http://www.cshp.ca/dms/dmsView/1_S_Unit_ Dose_2008.pdf

6. Guidelines for drug-use control. Ottawa (ON): Canadian Society of Hospital Pharmacists; 2008 [cited 2010 Dec 30]. Available from: www.cshp.ca/ dms/dmsView/1_1_DrugUseControl-25July08-CAL.pdf (membership required to access content).

7. Lummis H, Sketris I. Use of patients' own medications in Canadian hospitals: a national survey. Can J Hosp Pharm. 2008;61(2):114-22.

8. Lummis H, Sketris I, Veldhuyzen van Zanten S. Systematic review of the use of patients' own medications in acute care institutions. J Clin Pharm Ther. 2006;31(6):541-63.

9. Breau D, Nickerson A. Utilizing home medication supplies for hospital patients. Can J Hosp Pharm. 1997;50(5):224.

10. Fradgley S, Pryce A. An investigation into the clinical risks in the use of patient's own drugs on surgical wards. Pharm J. 2002;268:63-7.
11. McRobbie D, Bednall R, West T. Assessing the impact of re-engineering of pharmacy services to general medicine wards. Pharm J. 2003;270:342-5.

12. OPSEU Local 206 collective agreement. Hamilton (ON): Ontario Public Service Employees Union, Local 206; [cited 2011 Jun 14]. Available from: http://mystjoes/departments/hr/Pages/EmployeeLabourRelations.aspx. Accessed through MyStJoes intranet.

13. Drug Product Database [online query]. Ottawa $(\mathrm{ON})$ : Health Canada; [cited 2011 May 13]. Available from: http://webprod.hc-sc.gc.ca/dpd-bdpp/indexeng.jsp

14. Paton TW. In-hospital use of patient's own medication: Is it the right thing to do? [editorial]. Can J Hosp Pharm. 1997;50(5):195.

15. Canada Health Act. R.S.C., 1985, c. C-6. [cited 2011 May 17]. Available from: http://laws-lois.justice.gc.ca

16. Health Insurance Act. R.R.O. 1990, Reg. 552. [cited 2011 Jul 25]. Available from: www.e-laws.gov.on.ca/html/regs/english/elaws_regs_900552_e.htm\#BK1

17. Flood CM, Choudhry S. Discussion Paper No. 13: Strengthening the foundations: modernizing the Canada Health Act. Prepared for the Commission on the Future of Healthcare in Canada; 2002. Also available from: http:// publications.gc.ca/collections/Collection/CP32-79-13-2002E.pdf

18. Caulfield TA. Wishful thinking: defining "medically necessary" in Canada. Health Law J. 1996;4:63-85.

Gigi Y C Wong, BScPhm, ACPR, was, at the time this study was completed, a Hospital Pharmacy Practice Resident with St Joseph's Healthcare Hamilton. She is now a Clinical Pharmacist with the Fraser Health Authority at Langley Memorial Hospital, Langley, British Columbia.

Competing interests: None declared.

\section{Address correspondence to:}

Gigi Y C Wong

Pharmacy Department

Langley Memorial Hospital

Fraser Health Authority

22051 Fraser Hwy

Langley BC V3A 4H4

e-mail: gigiycwong1@gmail.com

\section{Acknowledgments}

Special thanks to Cathy Burger, Residency Coordinator, and Christine Wallace, Project Preceptor, for their assistance and guidance in the process. 